\title{
PERCEPÇÃO E GESTÃO AMBIENTAL DOS RECURSOS HÍDRICOS: DIÁLOGOS NO ESTUDO DE RESERVATÓRIO SUPERFICIAIS
}

\author{
Francisca Wigna da Silva Freitas ${ }^{(a)}$, Márcia Regina Farias da Silva ${ }^{(b)}$, Josiel de Alencar \\ Guedes $(c)$
}

\footnotetext{
(a) Faculdade de Ciências Exatas e Naturais. Universidade do Estado do Rio Grande do Norte - UERN. wignagreitas@yahoo.com.br

(b) Faculdade de Ciências Econômicas. Departamento de Gestão Ambiental. Universidade do Estado do Rio Grande do Norte - UERN. mreginafarias@ hotmail.com

(c) Departamento de Geografia. Universidade do Estado do Rio Grande do Norte - Campus Avançado Walter de Sá Leitão - UERN/CAWSL. josielguedes@ yahoo.com.br
}

\section{EIXO: BACIAS HIDROGRÁFICAS E RECURSOS HÍDRICOS: ANÁLISE, PLANEJAMENTO E GESTÃO}

\begin{abstract}
Resumo
Os recursos hídricos e a percepção ambiental são discussões que interligam as formas de uso e manejos dos recursos com o que é percebido pelo homem, na relação homem e meio. O presente artigo tem por objetivo construir um referencial teórico acerca da influência da percepção ambiental e sua importância metodológica nas pesquisas sobre recursos hídricos no semiárido brasileiro como subsídio para as discussões da temática. Como procedimentos metodológicos, o presente artigo utilizou-se de pesquisas bibliográficas e documental acerca do tema proposto, percepção ambiental e recursos hídricos, como, Okamoto (2002); Tuan (2012); Venturi (2006); Magalhães Jr (2007); Esteves (1998). Torna-se relevante a importância da percepção ambiental como aporte metodológico das discussões socioambientais, como auxílio nas interações do homem e do meio, e as reações sentidas por estarem interligados com os recursos hídricos oferecidos no reservatório Passagem e as relações socioeconômicas do entorno.
\end{abstract}

Palavras chave: Reservas hídricas, Gestão, Planejamento ambiental.

\section{Introdução}

O modelo econômico capitalista, que de forma descomedida utiliza-se dos recursos naturais, juntamente com a ausência de planejamento e gestão ambiental para o uso desses recursos, ao longo do espaço e do tempo, vem resultando em um desequilíbrio socioambiental (SANTOS, 2003) que, em relação aos recursos hídricos, mediante sua importância biológica, social, econômica e política, ocasiona instabilidade no meio natural e social; além disso, a qualidade e quantidade do recurso é essencial nesse processo (LANNA; BRAGA, 2006).

As consequências advindas das articulações do modelo econômico geraram discussões sobre a disponibilidade e qualidade dos recursos naturais existentes, iniciando a preocupação com o meio ambiente, sendo a década de 1990 marcada por essas discussões, ampliando as formas de observar o meio e ações antrópicas desenvolvidas no mesmo (CUNHA; COELHO, 2009). 


\section{OS DESAFIOS DA GEOGRAFIA FÍSICA NA FRONTEIRA DO CONHECIMENTO \\ Instituto de Geociências - Unicamp \\ Campinas - SP \\ 28 de Junho à 02 de Julho de 2017}

As discussões sobre as ações antrópicas no meio demostram as relações sociais desenvolvidas e os usos utilizados. Assim, analisar as formas de uso e os reflexos ocasionados no meio, partindo da visão de mundo dos agentes modeladores do espaço, o homem, possibilita compreendê-lo para conservá-lo.

Nesse sentido, a percepção ambiental ganhou visibilidade com essas discussões sobre o meio e a necessidade de compreendê-lo e conservá-lo, no qual podemos entendê-la como uma das técnicas desenvolvidas para inserir nas discussões científicas o agente antrópico, descrevendo e refletindo sobre o que é percebido pelo mesmo no ambiente, construindo assim, relatos dos que vivenciam as modificações ocorridas no meio pelas próprias ações antrópicas (OKAMOTO, 2002; TUAN, 2012).

A percepção ambiental acerca da utilização dos recursos hídricos, é relevante mediante a articulação homem-meio existente no entorno de reservas hídricas superficiais, microbacias, rios, bacias hidrográficas e outras formas de acumulação desse recurso, gerando uma discussão sobre as questões ambientais, sociais, econômicas, por meio dos usos dos recursos hídricos sem utilizar o planejamento e gestão ambiental dessas áreas (DICTORO; HANAI, 2016).

Os recursos hídricos são parte fundamental dos componentes e da modelagem da paisagem e do ambiente (DIAS; SILVA; GHEYI, 2011). A falta desse recurso ocasiona desequilíbrios sociais, econômicos e naturais (ANDRADE, 1981; DIAS; SILVA; GHEYI, 2011) sendo mais observados no semiárido nordestino, que apresenta déficit referente à distribuição sazonal de água, ocasionando impactos socioambientais relacionados à ausência, tanto do recurso como da gestão do mesmo (DIAS; SILVA; GHEYI, 2011).

O abastecimento hídrico na região está associado, principalmente, às reservas superficiais de água encontradas nas bacias, sub-bacias e microbacias hidrográficas. Nesse sentido, a bacia hidrográfica se destaca como a principal unidade de planejamento e gestão da água, como aporte para ser trabalhada a legislação com objetivos da busca por um desenvolvimento sustentável (MAGALHÃES, JR., 2007).

A microbacia é a unidade de análise que possibilita a compreensão das ações desenvolvidas no meio, estando interligadas as formas de gestão da bacia principal. Essa unidade que possibilita observar e desenvolver os parâmetros sobre a forma de usos dos recursos hídricos demostrados na legislação vigente (BOTELHO, 1999).

A legislação ambiental brasileira auxilia nos parâmetros necessários ao planejamento e à gestão dos recursos hídricos, podendo se destacar a Lei $\mathrm{N}^{\circ}$ 9.433/1997 que discorre sobre a forma de usos dos recursos hídricos e sobre ações que possam afetar a quantidade e qualidade da água (BRASIL, 1997), além do novo Código Florestal que dispõe sobre a proteção das matas nativas no entorno de corpos hídricos (BRASIL, 2012). 


\section{OS DESAFIOS DA GEOGRAFIA FÍSICA NA FRONTEIRA DO CONHECIMENTO \\ Instituto de Geociências - Unicamp \\ Campinas - SP \\ 28 de Junho à 02 de Julho de 2017}

A Lei No 9.433/1997 afirma que a água é um bem de todos, mas sua gestão também é dever de todos, compreendendo a necessidade de todas as partes que compõem a sociedade administrar e gerenciar os recursos naturais a partir de uma gestão integrada (BRASIL, 1997; FIGUEREDO JÚNIOR; DOURADO NETO, 2011).

Dessa forma, é possível apontar a necessidade de realizar uma análise desta problemática, pois os recursos hídricos dispõem da legislação vigente, tornando-se necessário ações diretas para o seu uso e manejo adequados, seja na bacia hidrográfica, microbacias ou reservatórios superficiais, justificando-se pela necessidade em si de realizar estudos voltados para o planejamento e a gestão dos recursos hídricos em regiões semiáridas, partindo da percepção ambiental dos agentes antrópicos que vivenciam e auxiliam para a melhoria dessas áreas.

Portanto, o presente artigo tem por objetivo discutir a influência da percepção ambiental e sua importância metodológica nas pesquisas sobre recursos hídricos no semiárido brasileiro como subsídio a discussões da temática sobre reservatórios em território potiguar, considerando-a relevante para a discussão das ações antrópicas e a dinâmica dos recursos hídricos no semiárido brasileiro.

\section{Metodologia}

Como procedimentos metodológicos, para elaboração do artigo utilizou-se de pesquisas bibliográficas e documental acerca dos temas propostos, a saber: percepção ambiental e recursos hídricos, em fontes como artigos de periódicos, livros, sites, dissertações, teses, e na biblioteca setorial do campus da Universidade do Estado do Rio Grande do Norte (UERN), para construção do referencial teórico, contemplando o objetivo proposto neste estudo.

Logo, é possível destacar os principais trabalhos utilizados nas discussões sobre percepções ambientais, que partiram de autores como, Okamoto (2002); Freitas; Ribeiro (2007); Rezende Filho; Fernandes (2010); Tuan (2012); Amaral; Bezerra; Steiner (2013); Lopes (2015); Dictoro; Hanai (2016); juntamente com os autores que discutem os recursos hídricos e sua gestão, Venturi (2006); Souza; Silva e Dias (2012); Lanna; Braga (2006); Magalhães Jr (2007); Cunha; Coelho, (2009); Figueredo Júnior; Dourado Neto (2011); Esteves (1998); Rosa et al (2015). Concomitantemente, utilizou-se de documentos, como as legislações vigentes, Brasil (1988; 1997; 2002; 2012) e Rio Grande do Norte (1996; 2010).

\section{Percepção ambiental na relação homem e meio}

A percepção ambiental é uma forma de observarmos o meio à nossa volta e desenvolvermos técnicas para compreendê-lo em sua dinâmica, como um sistema interdependente. Os estudos de percepção ganharam maior relevância a partir da compreensão de que o comportamento em sociedade modificava a dinâmica ambiental do meio, estando estes relacionados aos recursos e às técnicas que 
viabilizam os avanços para o desenvolvimento, seja ele econômico, ideológico, político ou social (OKAMOTO, 2002):

A percepção ambiental tem recebido destaque nos últimos 20 anos como técnica que associa a psicologia com a sociologia e a ecologia auxiliando na compreensão das expectativas e satisfações e insatisfações da população em relação ao ambiente em que vive e no reconhecimento dos fatores que afetam a qualidade de vida ou o bem estar social (FREITAS; RIBEIRO, 2007, p. 5).

Para Rezende Filho; Fernandes (2010) a "percepção ambiental é o estudo da relação entre o sujeito e o meio em que ele está inserido. Especificadamente, a forma como o sujeito percebe este meio, e a forma como ele se percebe no meio, individualmente e coletivamente" (p.44).

Segundo Tuan (2012) a percepção é uma base para a compreensão da forma como o ser observa e interage com o meio, observando o uso dos recursos e como os percebem, podendo observar as interferências ocorridas na dinâmica sociedade e meio.

Tuan (2012) desenvolveu uma análise da percepção partindo da historicidade e da percepção do meio do ser, da qual nos apropriamos para nos possibilitar refletir sobre o mundo vivido, principalmente pelas relações sociais, tornando-se uma ferramenta importante para a compreensão das formas de uso do meio e das ações recebidas por essas modificações.

A forma como o homem observa o meio é registrada nas imagens que ele captura dos espaços observados acumulando, assim, variáveis que detêm particularidades que servem como diferencial, particular, próprio. "Essas variáveis são integradas e resultam na estrutura cognitiva que permite percepções organizadas e significativas e assim, a interpretação da realidade" (BRANDALISE, 2008, p.122).

Os sentidos são peças fundamentais na percepção ambiental, que possibilitam a utilização das funções naturais do corpo humano para a compreensão do espaço habitado. Mesmo que o sentido da visão se sobressaía, os demais sentidos, como olfato, audição, paladar e tato, são necessários na construção do conhecimento de mundo e assim, da articulação dos mesmos na construção da realidade vivida (OKAMOTO, 2002; FREITAS; RIBEIRO, 2007).

As observações da interligação homem-meio são desenvolvidas por meio de vários métodos, partindo da própria observação e descrição do espaço e das relações existentes, isto é, de forma descritiva tanto das ações naturais como antrópicas, como também se pautando em dados estatísticos, como meio de quantifica-los, e por meio de uma abordagem que observa as ações e interage com os agentes modeladores dos mesmos, partindo não somente da observação do pesquisador, mas adentrando a percepção do pesquisado (MOREIRA, 1994; MORAES, 2005; MORAES, 2007). 


\section{OS DESAFIOS DA GEOGRAFIA FÍSICA NA FRONTEIRA DO CONHECIMENTO \\ Instituto de Geociências - Unicamp \\ Campinas - SP \\ 28 de Junho à 02 de Julho de 2017}

A abordagem, utilizando a percepção de agentes sociais, possibilita observar sob uma nova ótica as relações socioambientais existentes, auxiliando na compreensão da construção social e transformação natural (TUAN, 2012).

Os avanços na técnica, ciência e tecnologia desenvolveram no homem interferências na forma de sentir o meio a sua volta, em que a minimização do tempo e a articulação da informática diminuíram esses contatos, no qual "o resultado é sentirmos menos o meio ambiente" (OKAMOTO, 2002, p. 110).

Com isso, os estudos ambientais e sociais, vinculam a suas metodologias à percepção dos agentes antrópicos para compreender as alterações ocorridas no meio, de forma a observar o interlocutor que faz a ação e que sofre com essas ações, mediante a construção do conhecimento de que o homem modifica a natureza, porém modifica-se com ela (SUESS; BEZERRA; CARVALHO SOBRINHO, 2013).

As discussões acerca da percepção ambiental possibilitam adentrar o ambiente observado pelo homem, pelos grupos, pela sociedade, construindo a possibilidade de contribuir para a conservação dos recursos naturais utilizados, propondo medidas e inserindo a legislação na forma como é observado o meio, gerando assim resultados que visam garantir a qualidade e quantidade dos mesmos para as gerações futuras, contando com a colaboração das comunidades que os utilizam (GUIMARÃES, 2009; RISSO, 2011; BEZERRA, 2013; SUESS; AMARAL; BEZERRA; STEINER, 2013; LOPES, 2015; DICTORO; HANAI, 2016).

Dessa forma, os trabalhos desenvolvidos que interligam a percepção ambiental com os usos dos recursos naturais, em particular os hídricos, auxiliam na forma de observar o meio, no qual auxilia a discussão do manejo, planejamento e gestão dos mesmos.

\section{Caracterização da dinâmica dos recursos hídricos no semiárido brasileiro}

A utilização dos recursos naturais como forma de desenvolver a economia de um determinado lugar pode modificar significativamente os recursos a estes disponibilizados, em relação à quantidade e sua qualidade de uso para os seres (VENTURI, 2006; MILLER, 2007).

Os recursos naturais são utilizados mediante a necessidade de desenvolvimento dos corpos sociais, e a maneira de uso dispõe da técnica disposta por esta. A reposição destes recursos ocorre de forma natural, mas a sua utilização requer uma gestão ambiental e usos adequados para possibilitar uma inter-relação entre meio-homem mais equilibrada (FAO/IIASA, 1993).

Desse modo, os componentes naturais que são a base para todo o desenvolvimento, não só social, mas natural do nosso sistema planeta Terra, vem ao longo das transformações ocorridas no 
OS DESAFIOS DA GEOGRAFIA FÍSICA NA FRONTEIRA DO CONHECIMENTO Instituto de Geociências - Unicamp

Campinas - SP

28 de Junho à 02 de Julho de 2017

campo tecnológico, econômico e social sofrendo interferências significativas em relação ao seu controle de extração social e reposição natural (MILLER, 2007).

Entre os recursos naturais, os recursos hídricos, em particular, demonstram-se relevantes no desenvolvimento humano, perpassando as necessidades naturais dos seres, inserindo-se nas relações de construção social, política, cultural e econômica. Essas relações dos recursos hídricos e o desenvolvimento humano podem ser observadas de forma mais intensa em regiões semiáridas, por tratar-se de um recurso escasso e essencial para os seres vivos, diante da sua necessidade biológica e enquanto função social para o desenvolvimento econômico da sociedade, envolvido com a quantidade, qualidade e distribuição do mesmo (SANSORES, 2011).

Segundo Souza; Silva e Dias (2012, p.281) “os recursos hídricos são as águas superficiais ou subterrâneas disponíveis para qualquer tipo de uso em uma determinada região ou bacia hidrográfica", portanto, de suma importância para o equilíbrio ambiental do meio, como agente modelador das paisagens e de principal suporte econômico para o desenvolvimento.

A oferta dos recursos hídricos ao longo dos anos, é considerada ilimitada, pelo que, não se tem estabelecidas medidas que auxiliem no planejamento e gestão do mesmo. Assim, a falta da racionalidade na forma de utilizar esses recursos ocasionou, ao longo do tempo, um desequilíbrio social, natural e econômico (XAVIER; BEZERRA, 2005).

O uso de recurso hídrico requer, além da quantidade, a qualidade para ser utilizado como recurso natural para o ser humano. Assim, a discussão sobre os avanços da técnica e adaptação humana ao sistema produtivo, gerou um uso desenfreado e um abuso dos recursos naturais, impossibilitando o uso dos mesmos mediante os impactos gerados nos seus ciclos naturais (KORMONDY, 2002).

Além da qualidade ambiental dos recursos hídricos, em relação ao uso biológico relacionado ao consumo humano, é observada a relevância do mesmo para o desenvolvimento econômico, no qual, Tundisi et al (2006, p.216) afirmam que, "os vastos recursos hídricos do Brasil têm grande significado ecológico, econômico e social. O gerenciamento é, portanto, de importância fundamental para os reflexos na economia, na área social e nos usos dos sistemas aquáticos".

A importância dos recursos hídricos para o desenvolvimento econômico, utilizados desde a agricultura à recreação, encadeou vários impactos em seu ciclo, deixando subaproveitadas várias reservas hídricas, diante da impossibilidade da utilização tanto humana quanto econômica (SANSORES, 2011; LANNA; BRAGA, 2006).

Nas regiões semiáridas, os recursos hídricos, contam com déficit negativo, com precipitações anuais concentradas em um pequeno período do ano, apresentando duas estações bem perceptíveis: um período chuvoso, que vai de março a maio e um longo período seco. Além de apresentar um conjunto 
OS DESAFIOS DA GEOGRAFIA FÍSICA NA FRONTEIRA DO CONHECIMENTO Instituto de Geociências - Unicamp

Campinas - SP

28 de Junho à 02 de Julho de 2017

de rochas ígneas ou metamórficas, que têm por característica o escoamento e pouca infiltração, impossibilitando reservas superficiais desse recurso (CPRM, 2005).

As reservas superficiais de água localizam-se principalmente nas bacias, sub-bacias e microbacias hidrográficas, sendo a bacia hidrográfica considerada a principal unidade de planejamento e gestão da água, constituindo a área de atuação da legislação (MAGALHÃES, JR, 2007; FIGUEREDO JÚNIOR; DOURADO NETO, 2011). Entretanto, é possível observar nas sub-bacias e microbacias a disponibilidade de detalhes aprofundados, que acarretam uma análise do meio biótico e abiótico com relevância para as pesquisas ambientais e sociais (TEODORO et al, 2007).

A microbacia possibilita observar com escala de detalhes a dinâmica socioambiental existente, gerando subsídios para a gestão e planejamento mais viáveis para os recursos disponíveis, assim como delimitar as formas de usos utilizadas, e como é a relação social nessa área, se os usos geram conflitos e se os mesmos prejudicam a produção e desenvolvimento na microbacia (BOTELHO, 1999).

As reservas superficiais no Nordeste brasileiro caracterizam-se pelo barramento das águas superficiais advindas, principalmente, da precipitação anual, formando reservatórios, que vieram como uma política de combate à seca iniciada no período imperial, com a construção do açude Cedro no estado do Ceará. Essa forma de acumulação do recurso hídrico ganhou força e tornou-se característica da região semiárida, principalmente com as ações da Superintendência de Desenvolvimento do Nordeste (SUDENE) em parceria com o Departamento Nacional de Obras Contra a Seca (DNOCS) (ESTEVES, 1998; VIEIRA; GONDIM FILHO, 2006).

Essas reservas geram discussões mediante os conflitos gerados por meio das relações de seu uso. Os conflitos tornam-se mais visíveis em regiões com déficit hídrico, como a região semiárida, em relação à escassez do recurso, gerando discussões cientificas, políticas e econômicas que buscam analisar essa maneira de "dominar" os recursos naturais, cuja posse é disputada, mas as medidas para a gestão ambiental são esquecidas (MAURO, 2014).

Assim, a ascensão do desenvolvimento econômico vinculado à ausência de planejamento e gestão ambiental, interfere nos sistemas ambientais, a partir de ações como: desmatamento, crescimento desordenado das áreas urbanas, lixões a céu aberto, derramamento de esgotos in natura, gerando desequilíbrio nesses sistemas, gerando a escassez do recurso, mediante sua impossibilidade de utilização (TUNDISI et al, 2006).

Segundo Lanna; Braga (2006), os usos múltiplos dos recursos hídricos e a dependência das sociedades humanas e dos ecossistemas por meio de manejos impróprios para o desenvolvimento sustentável possibilita torná-lo cada vez mais escasso.

A falta de gestão faz com que ocorra uma degradação ambiental nas reservas hídricas, trazendo prejuízos tanto ao meio físico como ao meio social e econômico. Nesse sentido, o meio 


\section{OS DESAFIOS DA GEOGRAFIA FÍSICA NA FRONTEIRA DO CONHECIMENTO \\ Instituto de Geociências - Unicamp \\ Campinas - SP \\ 28 de Junho à 02 de Julho de 2017}

ambiente vincula o físico ao antrópico, interligando as ações sociais nas transformações ocorridas no natural (TUAN, 2012). Assim, intensificou-se a necessidade de se desenvolver ações que buscariam a melhoria nos usos dos recursos naturais, como os hídricos (microbacia; reservatórios), a partir de discussões sobre a qualidade ambiental, dos usos e manejos dos recursos, da forma da ocupação, buscando um desenvolvimento sustentável dos recursos naturais (ROSA et al, 2015).

O desenvolvimento da gestão dos recursos hídricos tem base na Constituição Federal de 1988, partindo da descrição de que, o dever de proteção dos recursos, incluindo os hídricos, deve ser de todos, pois ultrapassa a visão da água como bem privado, já que agora como de uso comum, exigindo a participação social na administração da gestão da mesma (BRASIL, 1988).

Na Lei N. 9.433/1997, a Lei das águas, a legislação parte para um direcionamento mais amplo do planejamento e gestão dos recursos hídricos. Dispõe os objetivos, as diretrizes e as formas de usos da água para assegurar a qualidade e quantidade do recurso para as futuras gerações, declarando na legislação o poder econômico que esse recurso possui; e suas influências nas transformações socioeconômicas, integrando também a sociedade como parte do processo de gestão, a partir da descentralização da mesma e criando o Plano de Recursos Hídricos como documento responsável pela construção das metas para o desenvolvimento de ações para o manejo do recurso (BRASIL, 1997).

A aplicabilidade da legislação ambiental reforça a necessidade da interligação da sociedade no planejamento e na gestão dos recursos, integrando todas as partes do sistema, incluindo a introdução das discussões com um viés comunitário, em que possibilita interagir com todos os elos do sistema social. "É consenso que a gestão de recursos hídricos é essencial a todos os setores da sociedade, devendo estar articulada com as políticas para os setores da educação, do meio ambiente, da indústria e do setor agrícola, dentre outros" (MONTENEGRO; MONTENEGRO, 2012, p.3).

Contudo, a participação efetiva da sociedade juntamente com o poder político são formas influentes na construção de um desenvolvimento e de uma gestão participativa dos recursos (CUNHA; COELHO, 2009). "Deste modo, a governança das águas se deve basear em princípios de gestão compartilhada, descentralizada e de ampla participação pública e dos usuários" (MONTENEGRO; MONTENEGRO, 2012, p. 5).

No estado do Rio Grande do Norte, a legislação vigente, mediante a gestão dos recursos hídricos está estabelecida na Lei 6.908 de primeiro de julho de 1996, contribuindo para a Política Estadual de Recursos Hídricos, a qual instituiu o Sistema Integrado de Gestão de Recurso Hídricos (SIGERN), com objetivo de planejar, desenvolver e gerenciar, os recursos hídricos com um caráter descentralizador e participativo para uma gestão visando conservar e preservar os recursos supracitados (RIO GRANDE DO NORTE, 1996). 


\section{OS DESAFIOS DA GEOGRAFIA FÍSICA NA FRONTEIRA DO CONHECIMENTO Instituto de Geociências - Unicamp \\ Campinas - SP \\ 28 de Junho à 02 de Julho de 2017}

Em nível de bacia hidrográfica as ações destinadas à busca pela gestão e o planejamento dos recursos hídricos estão presentes nos comitês de bacias hidrográficas. No Estado do Rio Grande do Norte, o comitê de bacias hidrográficas, do rio Apodi-Mossoró, foi criado pelo decreto $\mathrm{N}^{\mathrm{o}} 21.881$, de 10 de setembro de 2010, sendo formado pela União, o Estado, pelos municípios localizados na bacia hidrográfica, pelas entidades civis, e pelos usuários dos recursos da bacia (RIO GRANDE DO NORTE, 2010).

As ações realizadas nos Comitês de Bacias estabelecem medidas e discussões sobre o manejo sustentável para as bacias, em que, a microbacia inserida recebe esse suporte estabelecido, auxiliando no desenvolvimento do todo, que é a bacia hidrográfica.

Em relação às reservas hídricas superficiais, os reservatórios, a legislação está presente na Resolução 302/2002 preconizando os parâmetros, as definições e os limites de Áreas de Preservação Permanente (APP) em reservatórios e o regime de uso do entorno. Contudo, existe a definição de que "Reservatório artificial, é a acumulação não natural de água destinada a quaisquer de seus múltiplos usos". Quando observadas as reservas hídricas superficiais localizadas em áreas urbanas, a APP delimita que devem ter uma largura média de 30 metros, e em reservas localizadas em área rurais a largura é de 100 metros (BRASIL, 2002).

Dessa forma, a construção de diagnósticos, caracterizações e análises da gestão dos recursos hídricos, quanto à sua qualidade e quantidade, torna-se relevante na interligação das discussões acadêmicas, da legislação vigente, do desenvolvimento econômico e da percepção das comunidades, possibilitando a construção de uma gestão participativa dos mesmos, articulando-se no desenvolvimento de uma visão holística do meio, gerando diálogos, desafios e conquistas para a conservação dos recursos naturais.

\section{Considerações Finais}

É possível observar a importância da percepção ambiental como aporte metodológico das discussões socioambientais, como auxílio nas interações do homem e do meio, na construção de um diálogo condizente com as ações antrópicas desenvolvidas no ambiente, e as reações sentidas por estarem interligados ao estudo de recursos hídricos, principalmente relacionados a reservatórios superficiais e suas relações socioeconômicas.

Torna-se possível analisar as inter-relações socioeconômicas desenvolvidas, sobretudo no que se refere aos usos dos recursos naturais, e em particular os hídricos, mediante o planejamento e gestão dos mesmos, articulando a própria compreensão do meio exposto pelo homem, articulando a percepção ambiental e os recursos hídricos. 
Assim, as dificuldades existentes ocasionadas pelas características climáticas da região semiárida, por meio da má distribuição do recurso água gerando escassez do mesmo, possibilitam analises condizentes com as relações existentes entre o homem e os recursos, no qual a percepção ambiental torna-se caminho eficiente para a discutir as ações desenvolvidas pelos homens e as reações absorvidas pelos mesmos.

\section{Bibliografia}

AMARAL, J. R. B. C; BEZERRA, A. C. V; STEINER, A. Q. Percepção ambiental dos pescadores artesanais do litoral norte de Pernambuco - uma avaliação através da escala NEP. OLAM - Ciência \& Tecnologia. V. 1, n. 1, jan./jun. p.102-128, 2013.

ANDRADE, M. C. A produção do espaço norte-rio-grandense. Natal: Editora Universitária, 1981.

BOTELHO, R. G. M. Planejamento Ambiental em microbacia hidrográfica. In GUERRA, A. J. T; SILVA, A. S; BOTELHO, R. G. M. Erosão e Conservação dos Solos: conceitos, temas e aplicações. Rio de Janeiro: Bertrand Brasil, 1999, p. 269-300.

BRANDALISE, L. T. A percepção do consumidor na análise do ciclo de vida do produto. Cascavel: EDUNIOESTE, 2008.

BRASIL. Constituição (1988) Constituição da República Federativa do Brasil. 27 ed. São Paulo: Saraiva, 2007.

Lei $\mathbf{N}^{0}$ 9.433, de 8 de Janeiro de 1997. Dispõe sobre a forma de usos dos recursos hídricos e sobre ações que possam afetar a quantidade e qualidade da água. Disponível em: <http://www.planalto.gov.br/ccivil_03/leis/L9433.htm> Acesso em: 15. mar. 2016.

Resolução CONAMA N ${ }^{\circ} 302$ de 20 de março de 2002. Dispõe sobre parâmetros, definições e limites de Áreas de Preservação Permanente de reservatórios artificiais e o regime de uso do entorno Disponível em: <http://www.mma.gov.br/port/conama/legiabre.cfm?codlegi=298 >Acesso em: 20 mar. 2016.

Novo Código Florestal de 25 de março de 2012. Dispõe sobre a proteção da vegetação nativa; altera as Leis $\mathrm{n}^{\circ} \mathrm{s}$ 6.938, de 31 de agosto de 1981, 9.393, de 19 de dezembro de 1996, e 11.428, de 22 de dezembro de 2006; revoga as Lei $\mathrm{n}^{\circ} \mathrm{s} 4.771$, de 15 de setembro de 1965, e 7.754, de 14 de abril de 1989, e a Medida Provisória no 2.166- 67, de 24 de agosto de 2001; e dá outras providências. Câmara dos Deputados, Brasília, DF, 25 mai. 2012.

CPRM. Serviço Geológico do Brasil. Projeto Cadastro de Fontes de Abastecimento por Água Subterrânea. Diagnóstico do município de Itaú. Estado do Rio Grande do Norte. Recife: CPRM/PRODEEM, 2005. 11 p.

CUNHA, L. H.; COELHO, M. C. N. Política e gestão ambiental. In: CUNHA, S. B.; GUERRA, A. J. T. A questão ambiental: diferentes abordagens. $5^{\text {a }}$ ed. Rio de Janeiro: Bertrand Brasil, 2009, p. 43-79.

DIAS, N. S; SILVA, M. R. F; GHEYI, H. R. Recursos hídricos: usos e manejos. São Paulo: Editora Livraria da Física, 2011.

DICTORO, V. P; HANAI, F. Y. Análise da relação homem-água: a percepção ambiental dos moradores locais de Cachoeira de Emas - SP, Bacia hidrográfica do Rio Mogi-Guaçu. R. Ra e Ga. Curitiba, V. 36, p. 92-120, abr. 2016.

ESTEVES, F. A. Fundamentos de Limnologia. 2. ed. Rio de Janeiro: Interciência, FINEP, 1998.

FAO/IIASA. Agro-ecological assessments for national planning: the example of Kenya. Rome: FAO, 1993.

FIGUEREDO JÚNIOR, L. G; DOURADO NETO, D. Gerenciamento de recursos hídricos no Brasil. In: DIAS, N. S; SILVA, M. R. F; GHEYI, H. R. Recursos hídricos: usos e manejos. São Paulo: Editora Livraria da Física, 2011.

FREITAS, R. E.; RBEIRO, K. C. C. Educação e percepção ambiental para a conservação do meio ambiente na cidade de Manaus - uma análise dos processos educacionais no centro municipal de educação infantil Eliakin Rufino. Ed. 3, Revista Eletrônica Aboré. Nov. 2007. 
GUIMARÃES, S. T. L. Percepção ambiental: paisagens e valores. OLAM - Ciência \& Tecnologia. Rio Claro, Vol. 9, n. 2, p. 275-301, jan./jul. 2009.

KORMONDY, E. J. Recursos Naturais e ecologias de comunidades. In Ecologia humana. São Paulo: Atheneu Editora, 2002, p. 253-288.

LANNA, A. E. L; BRAGA, B. Hidroeconomia. In: REBOUÇAS, A. C; BRAGA, B; TUNDISI, J. G. (Org.). Águas doces no Brasil: capital ecológico, uso e conservação. $3^{a}$ ed. São Paulo: Escrituras Editora, 2006, p.607 637.

LOPES, T. C. S. Percepção e caracterização socioambiental como ferramenta auxiliar no planejamento e na gestão urbana - Assú/ RN. 130p. Dissertação - Programa de Pós-Graduação em Ciências Naturais. Mossoró, RN, 20 fev. 2015.

MAGALHÃES JÚNIOR, A. P. Indicadores ambientais e recursos hídricos: realidade e perspectivas para o Brasil a partir da experiência francesa. Rio de Janeiro: Bertrand Brasil, 2007.

MAURO, C. A. D. Conflitos pelo uso da água. Presidente Prudente, Caderno Prudentino de Geografia, n.36, p.81-105, 2014

MILLER, G. T. Ciência ambiental. São Paulo: Thomson Learning, 2007.

MONTENEGRO, A. A. A.; MONTENEGRO, S. M. G. L. Olhares sobre as políticas públicas de recursos hídricos para o semiárido. In. GREYI, H. R.; PAZ, V. P. S.; MEDEIROS, S. S.; GALVÃO, C. O. Recursos hídricos em regiões semiáridas. Campina Grande: Instituto Nacional do Semiárido; Cruz das Almas: Universidade Federal do Recôncavo da Bahia, 2012. P. 2-24.

MORAES, A. C. R. Ideologias Geográficas. São Paulo: Annablume, 2005.

MORAES, A. C. R. Geografia: pequena história crítica. Ed. 21ª São Paulo: Annablume, 2007.

MOREIRA, R. O que é geografia. Ed. 14. São Paulo: Brasiliense, 1994.

OKAMOTO, J. Percepção ambiental e comportamento: visão holística da percepção ambiental na arquitetura e na comunidade. São Paulo: Editora Mackenzie, 2002.

RIO GRANDE DO NORTE. Decreto No 21.881, de 10 de setembro de 2010. Cria o Comitê da Bacia Hidrográfica do Rio Apodi-Mossoró e dá outras providências. Disponível em:

<http://adcon.rn.gov.br/ACERVO/semarh/DOC/DOC000000000020592.PDF>. Acesso em: 20 Jun. 2016.

Política estadual de recursos hídricos, Lei no 6. 908, de 01/07/1996. Dispõe sobre a Política Estadual de Recursos Hídricos, institui o Sistema Integrado de Gestão de Recursos Hídricos - SIGERH e dá outras providências. Disponível em: <http://www.programaaguaazul.rn.gov.br/pdf/6908-96.pdf > Acesso em: 15 dez. 2016.

RISSO, L. C. Estudo de percepção ambiental do parque ecológico de Ourinhos -SP. Geografia. Rio Claro, v. 36, n. 2, p. 297-310, mai./ ago. 2011.

ROSA, A. H; SILVA, Â. A. M. J; MELO, C. A; MOSCHINI-CARLOS, V; GUANDIQUE, M. E. G; FRACETO, L. F; LOURENÇO, R. W. Diagnóstico ambiental e avaliação de uso e ocupação do solo visando a sustentabilidade da represa de Itupararanga, importante área da bacia do médio tietê. In: POMPEO, M; MOSCHINI-CARLOS, V; NISHIMURA, P. Y; SILVA, S. C; DOVAL, C. L. Ecologia de reservatório e interfaces. São Paulo: Instituto de Biociência da Universidade de São Paulo, 2015, p. 213-231.

SANSORES, J. C. H. Recursos hídricos: Hidrología subterrânea. In: POZO; CANTO; CALME, Riquezas biológicas de uintana roo: um análisis para su conservación, 2011.

SANTOS, Milton. Por uma outra globalização: do pensamento único à consciência universal. 10. ed. Rio de Janeiro: Record, 2003.

SILVA, A. S. Rio Grande do Norte. In: XAVIER, Y. M. A; BEZERRA, N. F. Gestão legal dos recursos naturais dos estados do Nordeste do Brasil. Fortaleza: Fundação Konrad Adenauer, 2005.

SOUZA, A. C. M.; SILVA, M. R. F.; DIAS, N.S. Gestão de recursos hídricos: o caso da bacia hidrográfica Apodi/Mossoró (RN). Irriga. Ed. especial, p.280-296, 2012.

VENTURI, L. A. B. Recurso natural: a construção de um conceito. No 20, São Paulo: GEOUSP - Espaço e Tempo, 2006, p. 09 - 17. 
VIEIRA, V. P. P. G; GONDIM FILHO, J. G. C. Água doce no semi-árido. In: REBOUÇAS, A. C; BRAGA, B; TUNDISI, J. G. (Org.) Águas doces no Brasil: capital ecológico, uso e conservação. $3^{a}$ ed. São Paulo: Escrituras Editora, 2006, p. 481-504.

TEODORO, V. L. I.; TEIXEIRA, D.; COSTA, D. J. L.; FULLER, B. B. O conceito de bacia hidrográfica e a importância da caracterização morfométrica para o entendimento da dinâmica ambiental local. Revista Uniara, v.20, p.137-157, 2007.

TUAN, Yi-Fu. Topofilia: um estudo da percepção, atitudes e valores do meio ambiente. Londrina: Eduel, 2012.

TUNDISI, J. G; TUNDISI, T. M; ABE, D. S; ROCHA, O; STRALING, F. Liminologia de águas interiores: impactos, conservação e recuperação de ecossistemas aquáticos. In: REBOUÇAS, A. C; BRAGA, B; TUNDISI, J. G. (Org.) Águas doces no Brasil: capital ecológico, uso e conservação. $3^{a}$ ed. São Paulo: Escrituras Editora, 2006, p. $203-240$. 